\title{
Development and evaluation of a formula for predicting introduction of medication self-management in stroke patients in the Kaifukuki rehabilitation ward
}

Hisato Fujihara ${ }^{1,2^{*}}$, Mari Kogo ${ }^{2,3}$, Isao Saito ${ }^{2}$, Nobuyuki Kawate ${ }^{4}$, Masazumi Mizuma ${ }^{4}$, Hiroko Suzuki ${ }^{1}$, Jun-ichiro Murayama ${ }^{2,5}$ and Tadanori Sasaki ${ }^{2,5}$

\begin{abstract}
Background: Medication self-management in stroke patients is important to prevent further progression of disease and incidence of side effects. The purpose of this study was to create a formula for predicting medication self-management introduction in stroke patients using functional independence measure items and patient data, including medication-related information.

Methods: This was a retrospective analysis of 104 patients (cerebral infarction, cerebral hemorrhage, subarachnoid hemorrhage) discharged from the Kaifukuki rehabilitation ward at Showa University Fujigaoka Rehabilitation Hospital from January to December 2012. Multivariate analysis was performed to develop a formula for predicting achievement of medication self-management.

Results: Of the 104 patients, 39 (37.5\%) achieved medication self-management. In the logistic regression analysis, number of drugs, age, walk/wheelchair mobility FIM, and memory FIM were extracted as significant factors independently contributing to achievement of medication self-management $(p<0.05)$. The prediction formula was [4.404 $-0.229 \times$ number of drugs at admission $+0.470 \times$ walk/wheelchair mobility FIM at admission + $0.416 \times$ memory FIM at admission $-0.112 \times$ age].
\end{abstract}

Conclusions: In the future, this formula may be used as an index to predict success of medication self-management in stroke patients.

Keywords: Stroke patient, Rehabilitation, Multivariate analysis, Predictive factor, Medication self-management, FIM

\section{Background}

Stroke patients admitted to a Kaifukuki rehabilitation ward often develop cognitive impairment. Therefore, there is a pressing need to improve patients' abilities to self-manage their social life and activities. Previous reports have shown that establishing goals during the early phase of hospitalization hastens effective rehabilitation [1-3].

\footnotetext{
* Correspondence: h-fujihara@cmed.showa-u.ac.jp

'Department of Pharmacy, Showa University Fujigaoka Rehabilitation Hospital, 2-1-1 Fujigaoka, Aoba-ku, Yokohama, Kanagawa 227-8518, Japan ${ }^{2}$ Department of Hospital Pharmaceutics, School of Pharmacy, Showa University, 1-5-8 Hatanodai, Shinagawa-ku, Tokyo 142-8555, Japan

Full list of author information is available at the end of the article
}

However, the medication self-management has not been appropriately evaluated for stroke patients, although it is important to prevent further disease progression and incidence of side effects.

Pharmacists who work in a Kaifukuki rehabilitation ward must support introduction of safe medication selfmanagement and prevent medication errors in stroke patients. In addition, the mission of hospital pharmacists is to help patients achieve optimal medication selfmanagement during hospitalization. However, decisions regarding whether to introduce medication selfmanagement for stroke patients should be based on optimal objective indicators. 
There are many studies reporting timing of discharge for stroke patients using admission data [4-15]. These reports use the functional independence measure (FIM), which objectively quantifies activities of daily living and is widely used in the rehabilitation ward as an evaluation criterion. Moreover, many studies used FIM items at admission to predict achievement of medication self-management in stroke patients [16-18]. However, there is currently no objective index for determining the likelihood of achieving medication self-management, including those measuring medication-taking behavior, such as number of drugs or number of doses per day.

The purpose of this study was to create a formula to predict if medication self-management would be effective for stroke patients using FIM items and patient data, including medication-related information.

\section{Methods}

\section{Patients}

The subjects included 104 patients (cerebral infarction, cerebral hemorrhage, subarachnoid hemorrhage) discharged from the Kaifukuki rehabilitation ward in Showa University Fujigaoka Rehabilitation Hospital from January to December 2012. A retrospective cohort study was conducted using data from the medical charts of the subjects. Subjects were excluded if they had a medication error during hospitalization after achievement of medication self-management. This study was approved by the ethics committee of Showa University Fujigaoka Hospital (approval no. 2012105).

\section{Clinical parameters}

We collected data from the medical charts, including age, sex, post-onset rehabilitation hospital day, type of disease (cerebral infarction, cerebral hemorrhage, subarachnoid hemorrhage), number of drugs, number of doses per day, number of doses to be taken once only, one-dose packages, and FIM item score as scored by nurses at the inpatient ward.

\section{Standards to introduce medication self-management}

Patients need to achieve all eight items shown in Table 1, and medical staff (physicians, pharmacists, nurses and occupational therapists) discuss and judge if safe medication self-management is applicable.

\section{Endpoint}

The endpoint of this survey was achievement of medication self-management at discharge.
Table 1 Eight items that are necessary to introduce drug action 口 Do you know purpose of drugs? YES/NO $\square$ Can you count the number of drugs? YES/NO $\square$ Do you know when to take drugs? YES/NO $\square$ Can you remember when to took drugs? YES/NO $\square$ Can you bring drugs to the mouth? YES/NO $\square$ Can you swallow drugs? YES/NO $\square$ Could you management daily medication by yourself? YES/NO $\square$ Could you continue taking drugs? YES/NO

\section{Univariate analysis}

We compared each variable between two groups: those achieving self-management and those who did not.

\section{Comparison of changes in the number of drugs and number of doses at admission, introduction of medication self-management, and discharge}

To exclude the influence of changes in medicine in the hospital, we compared the number of drugs and number of doses between admission and discharge. In addition, we compared the number of drugs and number of doses per day between admission and at the start of medication self-management.

Multivariate analysis and creation of a prediction formula Parameters that were significantly different in the univariate analysis were entered in the multivariate analysis. Significant independent variables contributing to medication self-management were extracted using stepwise selection methods. In addition, we composed a formula to predict medication self-management by using extracted items along with the regression coefficient. The prediction formula was $\mathrm{y}=\mathrm{aX} \mathrm{X}_{1}+\mathrm{bX}_{2}+\mathrm{cX} \mathrm{X}_{3}$, where $\mathrm{y}$ is the objective variable; $\mathrm{X}_{1}, X_{2}$, and $\mathrm{X}_{3}$ are the explanatory variables; and $\mathrm{a}, \mathrm{b}$, and $\mathrm{c}$ are regression coefficients. We used backward stepwise multiple regression analysis to select the variables.

\section{Evaluation of the validity of the prediction formula}

We evaluated the validity of the formula by using the degrees of freedom adjusted $\mathrm{R}^{2}$ statistic, lack of fit (LOF), and area under the receiver operating characteristic (ROC) curve, which provides an index indicating the association of the sensitivity and the specificity.

\section{Statistical analysis}

To examine between-group differences, the $t$-test was used for continuous variables, Fisher's exact test was used for categorical variables, and the Wilcoxon rank sum test was used for the FIM item score. A value of 
$p<0.05$ was considered statistically significant. JMP ${ }^{\circ} \mathrm{v}$. 9.0 (SAS Institute Inc., Cary, NC, USA) was used for the statistical analyses.

\section{Results}

\section{Patients characteristics}

Table 2 shows the characteristics of all patients. The average age was $70.0 \pm 12.3$ years; $65(62.5 \%)$ were men, and $39(37.5 \%)$ were women. Of the 104 patients, 39 (37.5\%) achieved medication self-management, and 65 (62.5\%) patients did not.

\section{Univariate analysis}

Table 3 lists the results of the univariate analysis. Age, post-onset rehabilitation hospital day, number of drugs, and number of doses per day were statistically different between the self-management group and the non-selfmanagement group $(p<0.05)$. All FIM items score were significantly different between the two groups (Table 3, $p<0.05)$.

\section{Comparison of changes in the number of drugs and number of doses from admission to discharge}

There was no significant difference between admission and discharge in the number of drugs and number of doses. In the medication self-management group, there was no significant difference between admission and the introduction of medication self-management (Table 4).

\section{Multivariate analysis and formation of a prediction formula}

In the logistic regression analysis, number of drugs, age, walk/wheelchair mobility FIM, and memory FIM were extracted as significant factors independently contributing to achievement of medication selfmanagement in stroke patients $(p<0.05)$. Table 5 lists odds ratios and $95 \%$ confidence intervals. We created

Table 2 Characteristics of the patients : host-related factors $(n=104)$

\begin{tabular}{ll}
\hline Variable & $n(\%)$ or Mean \pm SD \\
\hline Age (years) & $70.0 \pm 12.3$ \\
Sex & \\
$\quad$ Male & $65(62.5)$ \\
$\quad$ Female & $39(37.5)$ \\
Post-onset rehabilitation hospital day (days) & $23.5 \pm 9.4$ \\
Diagnosis & \\
$\quad$ Cerebral infarction & $65(62.5)$ \\
Cerebral hemorrhage & $34(32.7)$ \\
$\quad$ Subarachnoid hemorrhage & $5(4.8)$ \\
\hline
\end{tabular}

the prediction formula by extracting four factors and using the regression coefficient.

The formula was

$$
\begin{aligned}
{[4.404-0.229} & \times \text { number of drugs }+0.470 \\
& \times \text { walk } / \text { wheelchair mobility FIM } \\
& +0.416 \times \text { memory FIM }-0.112 \times \text { age }]
\end{aligned}
$$

\section{Evaluation of the validity of prediction formula}

In testing the validity of the prediction formula, the $\mathrm{R}^{2}$ value was 0.49 , and the $P$-value of LOF was 0.987 . The area under the ROC curve was 0.926 . Thus, our prediction model showed high accuracy.

\section{Discussion}

We created a formula to predict the likelihood of achievement of medication self-management for stroke patients using patient data, including items from the FIM item as well as drug-related information. It is often emphasized that pharmacists working in the Kaifukuki rehabilitation ward have an important role to support stroke patients to achieve medication self-management during hospitalization. In the current study, we confirmed the internal validity of a new prediction formula that may function as an appropriate index to predict whether patients will achieve medication selfmanagement at discharge. Pharmacists will be able to use this formula to help provide appropriate instruction to stroke patients.

The multivariate analysis revealed that the number of drugs at admission greatly influenced medication selfmanagement. There are some studies including each FIM item, but there is no report including drug-related information [16-18]. Accordingly, when pharmacists introduce medication self-management for stroke patients, it is important to consider the number of drugs at admission

Moreover, to exclude the influence of changes in drugs occurring during hospitalization, we compared changes in the number of drugs and in the number of doses from admission to discharge. However, there were no differences. Previously, Sato et al. reported that the number of drugs during hospitalization decreased by 0.47 per patient with pharmacist intervention; thus, it may be difficult to further decrease the number of drugs during hospitalization in the Kaifukuki rehabilitation ward [19]. Regardless, based on the current data, it is possible to predict medication self-management using drug-related information data at admission.

This study suggests that the fewer drugs at admission, the more likely a patient is to achieve 
Table 3 Comparison of variables between medication self-management and medication non-self-management groups

\begin{tabular}{|c|c|c|c|c|}
\hline & & $\begin{array}{l}S M \\
(n=39)\end{array}$ & $\begin{array}{l}\text { Non-SM } \\
(n=65)\end{array}$ & $P$ value \\
\hline & & $n$, Mean \pm SD & $n$, Mean \pm SD & \\
\hline \multirow[t]{5}{*}{ Characteristics of the patients } & Age (years) & $62.2 \pm 11.6$ & $74.7 \pm 10.1$ & $<0.001$ \\
\hline & Sex & & & 0.536 \\
\hline & Male & 26 & 39 & \\
\hline & Female & 13 & 26 & \\
\hline & Post-onset rehabilitation hospital day (days) & $23.5 \pm 9.4$ & $29.7 \pm 20.5$ & 0.040 \\
\hline \multirow[t]{4}{*}{ Medication-related item } & number of drug & $4.4 \pm 2.3$ & $6.5 \pm 3.3$ & $<0.001$ \\
\hline & number of doses per day & $2.3 \pm 1.4$ & $3.0 \pm 1.2$ & 0.008 \\
\hline & number of dose of medicine to be taken only once & $0.5 \pm 1.1$ & $0.7 \pm 0.8$ & 0.759 \\
\hline & one-dose packages/not one-dose packages & $33 / 6$ & $61 / 4$ & 0.170 \\
\hline \multirow[t]{18}{*}{ FIM item } & Eating & $6.2 \pm 1.3$ & $4.8 \pm 2.0$ & $<0.001$ \\
\hline & Grooming & $5.7 \pm 1.3$ & $3.8 \pm 2.0$ & $<0.001$ \\
\hline & Bathing & $4.7 \pm 1.7$ & $2.9 \pm 1.9$ & $<0.001$ \\
\hline & Dressing upper body & $4.9 \pm 1.6$ & $3.2 \pm 1.9$ & $<0.001$ \\
\hline & Dressing under body & $4.8 \pm 1.7$ & $2.9 \pm 1.9$ & $<0.001$ \\
\hline & Toileting & $5.6 \pm 1.7$ & $3.3 \pm 2.3$ & $<0.001$ \\
\hline & Bladder & $6.0 \pm 1.8$ & $4.0 \pm 2.6$ & $<0.001$ \\
\hline & Bowel & $5.7 \pm 2.1$ & $4.0 \pm 2.5$ & $<0.001$ \\
\hline & Bed chair transfer & $5.7 \pm 1.4$ & $3.7 \pm 1.7$ & $<0.001$ \\
\hline & Toilet transfer & $5.6 \pm 1.5$ & $3.5 \pm 1.8$ & $<0.001$ \\
\hline & Tub shower transfer & $4.7 \pm 1.5$ & $3.1 \pm 1.7$ & $<0.001$ \\
\hline & Walk/wheelchair mobility & $5.3 \pm 1.9$ & $2.7 \pm 1.9$ & $<0.001$ \\
\hline & Stairs & $2.3 \pm 2.3$ & $1.2 \pm 0.9$ & 0.002 \\
\hline & Comprehension & $6.1 \pm 1.2$ & $4.6 \pm 2.0$ & $<0.001$ \\
\hline & Expression & $6.0 \pm 1.5$ & $4.8 \pm 2.1$ & 0.003 \\
\hline & Social interaction & $6.7 \pm 1.0$ & $5.2 \pm 2.2$ & $<0.001$ \\
\hline & Problem solving & $5.7 \pm 1.4$ & $3.5 \pm 2.1$ & $<0.001$ \\
\hline & Memory & $5.9 \pm 1.4$ & $3.8 \pm 2.0$ & $<0.001$ \\
\hline
\end{tabular}

SM medication self-management group

medication self-management. Some studies report the relation between the number of drugs and medication behavior [20, 21]. For example, Horne et al. reported that adherence is more influenced by the values that the patient places on their medicine than their characteristics [20]. Kamishima et al. reported that medication adherence of stroke patients decreased as the number of drugs increased [21] and that there are three characteristic in patients with poor adherence: 1) those who feel the number of medicines is too

Table 4 Comparison of changes in the number of drugs and number of doses from admission to discharge

\begin{tabular}{|c|c|c|c|c|c|c|}
\hline & & Admission & $\begin{array}{l}\text { Self-management introduced } \\
\text { taking the drug }\end{array}$ & $P$ value & Discharge & $P$ value \\
\hline & & Mean \pm SD & Mean \pm SD & & Mean \pm SD & \\
\hline \multirow{2}{*}{$\begin{array}{l}\mathrm{SM} \\
(n=39)\end{array}$} & Number of drugs & $4.4 \pm 2.3$ & $4.8 \pm 2.4$ & 0.147 & $5.0 \pm 2.6$ & 0.068 \\
\hline & Number of doses per day & $2.3 \pm 1.4$ & $2.3 \pm 1.2$ & 0.744 & $2.2 \pm 1.1$ & 0.680 \\
\hline \multirow{2}{*}{$\begin{array}{l}\text { non-SM } \\
(n=65)\end{array}$} & Number of drugs & $6.4 \pm 3.3$ & - & - & $6.9 \pm 2.7$ & 0.084 \\
\hline & Number of doses per day & $3.0 \pm 1.2$ & - & - & $3.1 \pm 1.2$ & 0.494 \\
\hline
\end{tabular}


Table $\mathbf{5}$ Results of stepwise multiple regression analyses

\begin{tabular}{lccll}
\hline Factor & $\begin{array}{c}\text { Regression } \\
\text { coefficient }\end{array}$ & Odds ratio & $\begin{array}{l}\text { 95\% confidence } \\
\text { interval }\end{array}$ & $P$ value \\
\hline Number of drugs & -0.229 & 0.795 & $0.629-0.969$ & 0.035 \\
$\begin{array}{l}\text { Walk/wheelchair } \\
\text { mobility FIM }\end{array}$ & 0.470 & 1.600 & $1.186-2.251$ & 0.004 \\
Memory FIM & 0.416 & 1.517 & $1.073-2.225$ & 0.023 \\
Age & -0.112 & 0.894 & $0.837-0.944$ & 0.0002 \\
Intercept & 4.404 & & & 0.045 \\
\hline
\end{tabular}

much, 2) those who have not received instruction by pharmacists and 3) those who feel anxiety taking medication for a long time [21]. When pharmacists introduce medication self-management for stroke patients, poor adherence is an important problem. Considering the above discussion, decreasing the number of drugs before hospitalization improves medicine self-management. This previous study supports the current results and increases the validity of the prediction formula.

In the current study, age was significantly lower in the self-management group than in the non-self-management group. Aging is associated with poor medication adherence caused by factors such as declining cognitive function and dysphagia [22, 23]. Accordingly, age is an important factor in considering introduction of medication self-management $[22,23]$.

In addition, the memory FIM item was associated with medicine self-management. This is similar to a previous study on achievement of medication selfmanagement using the FIM [16-18]. The memory FIM item evaluates ability to memorize and reproduce linguistic and visual information in everyday life, a skill which is required to take medications correctly. In addition, it is also important to correctly understand pharmacist's instructions, such as how and when to take a medicine. Accordingly, the FIM score is also an important factor in considering introduction of medication self-management.

This study has some limitations. The prediction formula was created for the patients in our hospital, but it was not subjected to external validation using data from other facilities. Therefore, there is a need to validate the formula if it is to be useful as a benchmark in other facilities. Furthermore, we did not examine the influence of the endpoint based on the rehabilitation program or that of patient education provided by pharmacists. Nonetheless, despite the limitations, the current prediction formula can be an effective tool to determine the likelihood of medication selfmanagement in stroke patients at admission. Additionally, the formula may also help to prevent medication error.

\section{Conclusion}

The number of drugs at admission greatly influenced achievement of medication self-management in stroke patients. In addition, the prediction formula developed herein may be useful to predict whether to introduce medication self-management for stroke patients.

\section{Abbreviations}

FIM: Functional independence measure; LOF: Lack of fit; ROC: Area under the receiver operating characteristic

Acknowledgements

Not applicable.

\section{Funding}

There are no funding sources for this report.

Availability of data and materials

Patients information cannot be shared.

\section{Authors'contributions}

HF carried out the data management, performed the statistical analysis and drafted the manuscript. HF, MK, JM designed the research. MK, IS, NK, MM, HS, JM, and TS helped to draft the manuscript. All authors read and approved the final manuscript.

\section{Competing interests}

The authors declare that they have no competing interests.

Consent for publication

Not applicable.

Ethics approval and consent to participate

This study was approved by the ethics committee of Showa University Fujigaoka Hospital (approval no. 2012105).

\section{Author details}

${ }^{1}$ Department of Pharmacy, Showa University Fujigaoka Rehabilitation Hospital, 2-1-1 Fujigaoka, Aoba-ku, Yokohama, Kanagawa 227-8518, Japan. ${ }^{2}$ Department of Hospital Pharmaceutics, School of Pharmacy, Showa University, 1-5-8 Hatanodai, Shinagawa-ku, Tokyo 142-8555, Japan. ${ }^{3}$ Department of Pharmacy, Showa University Fujigaoka Hospital, 1-30 Fujigaoka, Aoba-ku, Yokohama, Kanagawa 227-8501, Japan. ${ }^{4}$ Department of Rehabilitation Medicine, School of Medicine, Showa University, 2-1-1

Fujigaoka, Aoba-ku, Yokohama, Kanagawa 227-8501, Japan. ${ }^{5}$ Department of Pharmacy, Showa University Hospital, 1-5-8 Hatanodai, Shinagawa-ku, Tokyo 142-8666, Japan.

Received: 1 October 2016 Accepted: 19 December 2016 Published online: 10 January 2017

\section{References}

1. Nakamura R, Nagasaki H, Amakusa B. Shinpan Nosotyu-no Kinohyoka to Yogoyosoku (Assessment and Prediction of functional State in Stroke). Tokyo: Ishiyaku Publishers, INC.; 2011.

2. Kwakkel G, Wagenaar R, Kollen B, Lankhorst G. Predicting disability in stroke-a critical review of the literature. Age Ageing. 1996;25:479-89.

3. Shinohara Y, Ogawa A, Suzuki N, Katayama Y, Kimura A. Japanese Guidelines for the Management of Stroke 2009. Tokyo: Kyowa Kikaku; 2009. p. 281-2.

4. Tokunaga M, Sannomiya K, Nakanishi R, Yonemitsu H. The external validity of multiple regression analyses predicting discharge FIM score in patients with stroke hospitalized in Kaifukuki rehabilitation wards - An analysis of the Japan Rehabilitation Database -. Jpn J Compr Rehabil Sci. 2015;6:14-20.

5. Jeong S, Inoue $Y$, Kondo K, Matsumoto D, Shiraishi N. Formula for predicting FIM for stroke patients at discharge from an acute ward or convalescent rehabilitation ward. Jpn J Compr Rehabil Sci. 2014;5:19-25.

6. Sonoda S, Saitoh E, Nagai S, Okuyama Y, Suzuki T, Suzuki M. Stroke outcome prediction using reciprocal number of initial activities of daily living status. J Stroke Cerebrovasc Dis. 2005;14:8-11. 
7. Iwai N, Aoyagi Y. Discharge index and prediction for stroke patients in the post-acute stage. Jpn J Compr Rehabil Sci. 2012;3:37-41.

8. Inouye M. Predicting models of outcome stratified by age after first stroke rehabilitation in Japan. Am J Phys Med Rehabil. 2001;80:586-91.

9. Liu M, Domen K, Chino N. Comorbidity measures for stroke outcome research. Arch Phys Med Rehabil. 1997;78:166-72.

10. Sonoda S, Saitoh E, Domen K, Chino N. Prognostication of stroke patients using SIAS and FIM. In Functional Evaluation of Stroke Patients (ed by Chino N, Melvin JL). Springer-Verlag, Tokyo; 1996. p.103-14.

11. Jeong S, Kondo K, Shiraishi N, Inoue Y. An evaluation of post-stroke rehabilitation in Japan. Clin Audit. 2010;2:59-66.

12. Tsuji T, Liu M, Sonoda S, Domen K, Chino N. The stroke impairment assessment set. Arch Phys Med Rehabil. 2000;81:863-8.

13. Mutai H, Furukawa T, Araki K, Misawa K, Hanihara T. Factors associated with functional recovery and home discharge in stroke patients admitted to a convalescent rehabilitation ward. Geriatr Gerontol Int. 2012;12:215-22.

14. Tokunaga M, Fukunaga K, Sannomiya K, Imada Y, Hamasaki H, Noguchi D, et al. The difference between measured Nichijo-seikatsu-kino-hyokahyo (NSKH) score and predicted NSKH score derived from ADL is related to FIM gain. Jpn J Compr Rehabil Sci. 2013;4:61-6.

15. Hirano $Y$, Okura $Y$, Takeuchi $M$. The influence of ADL severity at admission on ADL at discharge in convalescent stroke rehabilitation. Tohoku Rigakuryoho Kagaku. 2011;23:32-7.

16. Ochiai K, Aoki M, Yazawa T, Komuro R, Kobayashi E, Kaneko S. The Step by Step Self-Management System of Medication for the Patients Suffering from the Aftereffects of Cerebrovascular Disease. Acta Scientiarvm Valettvdinis Universitatis Praefectvralis Ibarakiensis: ASVPI. 2004;9:21-35.

17. Yamabe $T$, Tokunaga M, Furusato $K$, Miyamoto M, Ikeda $Y$, Kozono M, Ueda H, Harada S. Nousothu no Fukuyakujikokanri he muketa Tasyokusyu ni yoru Kainyu no Kouka: FIM no Ninchikoumoku wo Kaishikijyun to shite. Brain Nursing. 2007;23:89-95.

18. Furusato K, Tokunaga M, Kuwata T, Yamabe T, Miyamoto M, Ueda H, Harada S. Fukuyakujikokanri ga Jiritsu suru Nosotyu no Yosokusiki: FIM no Undo 3 Komoku to Ninchi 2 Komoku wo mochiite. Brain Nursing. 2007;23:103-8.

19. Sato T, Sato K, Sato A. Medication Reduction in a Convalescent Rehabilitation Ward. Nippon Ronen Igakkai Zasshi. 2010;47:440-4.

20. Horne R, Weinman J, Hankins M. The beliefs about medicines questionnaire: The development and evaluation of a new method for assessing the cognitive representation of medication. Psycol Health. 1999;14:1-24.

21. Kamishima S, Noji A, Katakura Y, Maruyama T. Factor Related to Adherence to a Medication Regimen in Out-patients Being Treated for Stroke. J Jpn Acad Nurs Sci. 2008;28:21-30.

22. Kato S. Yakuzaishi kara mita Koureisya no Fukuyakushien: Genjyo to Kadai. Geriat Med. 2008;46:761-3.

23. Osterberg L, Blaschke T. Adherence to Medication. N Engl J Med. 2005;353: 487-97.

\section{Submit your next manuscript to BioMed Central and we will help you at every step:}

- We accept pre-submission inquiries

- Our selector tool helps you to find the most relevant journal

- We provide round the clock customer support

- Convenient online submission

- Thorough peer review

- Inclusion in PubMed and all major indexing services

- Maximum visibility for your research

Submit your manuscript at www.biomedcentral.com/submit
Biomed Central 